\title{
A Framework for the Study of Expansion Options, Loan Commitments and Agency Costs*
}

\author{
Masahiko Egami ${ }^{\dagger}$
}

\begin{abstract}
We consider a firm that operates a single plant and has an expansion option to invest in a new plant. This setup leads to two-sided optimal stopping problems. We analyze optimal expansion timing and quantify the value of the loan commitment that the equityholder obtained from the lender and associated agency costs incurred on the lender's side. Moreover, we incorporate construction period for the new plant, which throws another layer of uncertainty into the model: the parties cannot tell price level of the firm's product when the construction completes. This analysis contrasts with the conventional one-sided stopping models in corporate finance literature. We can study expansion options by viewing a firm's existing operation, bankruptcy threat, and financing decisions all together.
\end{abstract}

Key Words: Irreversible investment, bankruptcy cost, agency cost, optimal stopping, loan commitment

JEL Classification: D81, D92, G31, G33

\section{Introduction}

Conflicts of interest between bond and equity holders and the agency costs associated with use of debt have long been recognized in economic literature. To shed additional light on this topic, we formulate an optimal stopping problem where managers/equityholders have an option to expand a plant using either debt or equity financing and seek an optimal exercise time. In exercising the expansion option, there are three cases: (A) the firm uses debt-financing with a view to maximizing the equity value (rather than the firm value); (B) the firm uses debt-financing to maximize the firm value; and (C) the firm equityfinances the expansion. Note that we use the terms, debtholder and lender interchangeably and similarly, equityholder, borrower, and manager indicate the same entity. For practical use, we attempt to answer the following questions:

- how to compute the optimal timing of expansion in each of (A), (B) and (C) and how much are the equity and debt values?

- how to compute the value of the commitment letter (from the lender to the borrower) and the value lost to the lender due to the lack of control over investment decisions?

\footnotetext{
* An earlier version of this paper is circulated under the title "Corporate Investment Policy Distortion and Indirect Cost of Bankruptcy" (First version: May 2006). We thank Kian Esteghamat and Wenlong Weng for valuable comments and discussions.

${ }^{\dagger}$ Graduate School of Economics, Kyoto University, Yoshida-honmachi, Sakyo-ku, Kyoto 606-8501, Japan. Tel:+81-75-7533430, Fax: +81-75-753-3490, Email:egami@econ.kyoto-u.ac.jp.
} 
- what if the level of uncertainty regarding price fluctuations increases?

- what if one needs to wait for completion of the plant construction; how much would the risk level increase?

- how do these numbers vary with different initial output price levels?

- what are the possible economic explanations behind these numbers?

Based on numerical values provided by our analysis, the equityholder (borrower) finds the optimal expansion strategy and the lender can negotiate with the borrower the terms and conditions of the proposed debt. We provide a unified approach and framework to the expansion and financing problem. When different assumptions about underlying price process are made, the analysis can be modified easily since our method works for general linear diffusions.

\subsection{Background}

It is often stated that, lacking countervailing incentives, managers of levered firms prefer risky projects to stable cash flows. Acting on behalf of shareholders, firm managers tend to underinvest in safer projects and overinvest in risky ones. In this paper, we call overinvestment a situation where the firm uses its expansion option earlier in Case (A) than in Case (B) or (C). Similarly, we call underinvestment when the firm does the opposite in Case (A) than in Case (B) or (C). Because of the limited liability feature of corporate borrowing, shareholders benefit from higher equity values as volatility increases, even though the value of existing debt may diminish. The model of the firm we employ incorporates an endogenous bankruptcy trigger whereby equityholders choose the timing of default on debt obligations (Black and Cox [1], Mello and Parsons [20], Leland [15], Mella-Barral and Perraudin [19]).

Various agency problems can affect shareholders, managers, and debtholders of a firm. To focus on the role of bankruptcy risk, we restrict our attention, in this study, to limited liability as a source of agency cost. ${ }^{1}$ We summarize what would be issues when the debt holder does not have control over investment decisions and the equityholder has limited liability. Since shareholders are not personally liable for the firm's debt obligations, they collectively hold embedded call options on asset value. The option is exercised by transferring the firm to creditors if value of assets falls below debt obligations. Black and Scholes [2] and Merton [21] point out the importance of limited liability in determining the value of corporate debt but, in accord with the view that capital structure is irrelevant, they assume firm value is exogenous. Challenging this assumption, Jensen and Meckling [13] describe the potential for reduction in firm value through "asset substitution." They examine agency costs including incentive effects of debt on investment choices of equityholder-manager and assert that equityholders can extract value from debtholders by using existing debt funds to overinvest in risky projects. It is limited liability that produces greater value for shareholders from an increase in risk exposure. Firm value is reduced and wealth is transferred from creditors to equityholders as bankruptcy risk grows. On the other hand, since shareholders are residual claimants to firm value after debt is paid, debtholders benefit more from a safe positive net value project than shareholders. An unlevered firm considers only the project cost. With leverage, managers invest in an equity-financed project if its value exceeds the sum of project cost and payments promised to creditors. Thus, a higher hurdle has to be overcome before a new project is

\footnotetext{
${ }^{1}$ For a review of corporate finance and related agency problems see Brennan[3] and Zingales [26]. In this paper, equityholders are managers who make those decisions. Therefore we do not have manager-equityholder conflicts. See Cadenillas et al. [5] and Morellec [22] for discussion on manager-equityholder conflicts.
} 
undertaken. Myers [23] argues that for this reason leverage causes a debt overhang or underinvestment problem and views the firm as a collection of existing assets, liabilities, and growth opportunities. ${ }^{2}$ When financed with equity, the connection between assets and liabilities in this arrangement inhibits value-maximizing use of growth options.

Only relatively recently have attempts been made to quantify the impact of this problem and early evidence has been mixed. Employing a model in which firm managers maximize equity value after debt is in place, Leland [16] finds that the magnitude of agency costs due to asset replacement is small. Parrino and Weisbach [24] simulate the effect of shareholder-bondholder conflicts on a levered firm using discounted cash flow analysis where the growth option is a 'now or never' equity-financed investment in a risky project. They compute the expected transfer of wealth between bondholders and shareholders and conclude that, for most firms, the effect is small. Several papers explore the interplay of financing and investment/operating policies in a dynamic decision environment and arrive at a different conclusion. Mello and Parsons [20] build on the contingent claims model of Brennan and Schwartz [4] of a mine to investigate how debt financing influences operating decisions and find that agency costs are comparable or greater than underwriting and other direct administrative expenses of leverage. Using a flexible discrete time, discrete state, finite horizon model, Childs et al. [6] show that the agency costs of asset substitution and underinvestment have a substantial effect on optimal leverage and firm value. In the construction of [6], the firm optimizes its initial leverage ratio. Titman and Tsyplakov [25] study the incentive to underinvest by allowing managers to dynamically adjust the firm's leverage and observe significantly higher agency costs in comparison to values suggested by static debt models. To study the overinvestment problem, Mauer and Sarkar [17] consider a firm whose only asset is a real option in the form of an opportunity to invest in a production facility. They optimize leverage, debt maturity, and timing of exercise of the option to find that the agency cost of debt is a significant fraction of firm value. Recently, Hennessy [12] empirically finds a statistically significant relationship between debt overhang and investment distortion.

\subsection{Contributions to the literature}

We consider a firm that operates a single plant and has an expansion option to invest in an identical plant. This setup naturally leads to two-sided optimal stopping problems which have been rarely considered in the corporate finance literature. Our objective goes beyond the extensively discussed overinvestment/ underinvestment issues. Our approach here is to clarify the interplay between the equityholder (borrower) and the lender by comparing various value functions. More specifically, first, we quantify the value of the loan commitment that the equityholder obtained from the lender. Upon receiving a commitment to debt financing, the equityholder becomes entitled to tax shield. Secondly, from the lender's point of view, the lack of control over investment decisions may cause agency cost. That is, the agency cost can be defined as the difference in values between two optimization policies: firm value versus equity value maximization. Our framework allows one to quantify this value at all the initial output price levels. Furthermore, we consider the case when there exists a nonzero construction period in implementing the firm's expansion plan. This assumption is realistic and throws additional uncertainty into the model since the parties do not know price level of the product at the time the construction is completed. As we shall see, for example in the third and fourth bullet points in the next page, risk factors (output price volatility and construction period) affect the debt value as well as the equity value. Hence the overall impact of the increased risk level on the agency cost should be understood by taking this matter into account.

\footnotetext{
${ }^{2}$ We adopt a slight restatement of this definition and treat the firm as a collection of existing assets, liabilities, and real options to emphasize that, in addition to growth opportunities, other operating and investment options are available to the firm.
} 
What makes the above analysis possible is the fact that we solve associated optimal stopping problems in a mathematically rigorous manner, proving the existence and uniqueness of the solutions. Since we compute all the associated value functions, we can view the value of equity (coupled with the expansion option) at all the initial output price levels and, therefore, grasp the entire picture about what is happening. Here we stress that, in contrast, most papers rely solely on numerical implementations in finding solutions. Accordingly, the analysis we perform here could not be easily handled, especially the case of a positive construction period. Another difference from the extant literature is that similar setups usually involve one-sided optimal stopping. In their usual setup, a firm is assumed to have an investment option but it is unclear how the new investment is positioned against existing operations and capital structure. We contrast these models with our two-sided problems that allow a more comprehensive study of real options by viewing a firm's existing operation, expansion option, bankruptcy threat and financing decisions all together. One of the practical merits of this framework is that it provides numerical values (equity, debt, loan commitment and agency cost) based on which the equity and bond holders can negotiate over financing terms. We believe that the aforementioned points are unique contributions in the field of expansion options and financial decisions. Here let us highlight some results that are newly obtained by our model and its implementation:

- Without tax shield, whether the firm's expansion timing with debt financing is earlier (overinvestment) or not, relative to equity financing, depends nonlinearly to uncertainty measured by the volatility parameter in the output markets. (Table 1 , the columns with $\theta=0$ as well as Figure 1). Note also that the potential for early investment in the debt financing is greater in small investments.

- In the presence of tax shield, we confirm that overinvestment is the likely outcome (Table 1 , the columns with $\theta=0.3$ ) because the tax shield makes debt financing more attractive and prompts the managers to exercise the expansion option early. It is worth noting that while the coupon levels $\bar{c}$ in this case are higher than those in the case of $\theta=0$, the differences are very small across all volatility levels. This implies that debt value does not increase much.

- We quantify the value of the loan commitment that the equityholder obtained and associated agency cost (Figure 2). It is observed that the agency cost is small relative to the value of the loan commitment. Further, we perform a sensitivity analysis by raising the volatility level and find that the value of having loan commitment increases at all initial output prices as the volatility becomes higher. However, the agency cost is reduced in the low output price range (Figure 3). A possible explanation is that when the output price is low, the value of the debt is also low due to the increased risk of default and this situation should be worsened by the increased volatility. This leads to a lower value of firm value maximization policy and results in lower agency cost.

- If we incorporate a positive construction period into the model, the value of the equity (with the expansion option) declines due to the increased uncertainty level. We find that the agency cost shrinks. An explanation similar to the previous paragraph is possible here. This phenomenon is observed more clearly when the volatility level is higher. See Figures 4 and 5.

The structure of the paper is as follows: We present our model in Section 2, solve the two-sided optimal stopping problem and explain how to implement the model to compute the value of having loan commitment and associated agency cost. In Section 3, we provide numerical results and empirical implications. Mathematical proofs are saved for the appendix that follows concluding remarks. 


\section{Model}

Let $\left(\Omega, \mathcal{F},\left(\mathcal{F}_{t}\right)_{t \geq 0}, \mathbb{P}\right)$ be a complete filtered probability space with a standard Brownian motion $W=$ $\left\{W_{t} ; t \geq 0\right\}$. Consider a firm that owns one plant and produces a unit of output which it sells for $P_{t}$ at time $t$. For simplicity, assume the market price $P_{t}$ evolves exogenously over time as a geometric Brownian motion

$$
\mathrm{d} P_{t}=\mu P_{t} \mathrm{~d} t+\sigma P_{t} \mathrm{~d} W_{t}
$$

where $\mu$ and $\sigma$ are constant parameters. Denoting by $\xi$ the unit cost of output produced, the firm's profit flow is $P_{t}-\xi$. Given a positive production $\operatorname{cost}(\xi>0)$, the firm liquidates all assets the first time output price falls below some constant low level. At closure, the firm has a salvage value of $\gamma$.

The firm has an opportunity to expand operations by adding a new plant at cost $I$. The new plant, which produces one unit of output identical to the original plant, also has a salvage value $\gamma$ at closure. The firm's decision problem is to determine when to invest in the additional plant. Once made, the investment is irreversible except that the firm can permanently cease all production activity by simultaneously shutting down both plants. Of course, equityholders may liquidate the firm before investment is made in the new plant if profits of the single plant are too low. The investment, if made, can be funded by issuing equity or debt. The firm has no preexisting debt. In addition, we assume that managers of the firm are its equityholders and do not distinguish between shareholders and managers. Once in operation, a plant must be run at full capacity. There is no possibility of scaling back production other than shutting down all operations and liquidating the firm. If funded by debt, bondholders immediately liquidate the firm upon bankruptcy. This effectively means that the direct cost of bankruptcy is sufficiently high to warrant closing down the plant.

\subsection{Debt Financing}

Let us consider the firm's decision if investment where to be fully funded (100\%) debt. This analysis can be easily extended to the case where investment is partially funded by debt and partially by equity (see Section 4). Debt is issued just prior to investment in the new plant. We assume debtholders are fully informed about the financial state of the firm and its prospects and are, thus, able to determine the correct value of debt.

We work backwards, starting the analysis with a firm that already owns two plants, has a profit flow of $2 P_{t}-2 \xi$, and has issued perpetual debt with principal $c / r$ and a contractual coupon flow $c$ per period of time. Managers operate the firm in order to maximize shareholder equity value (rather than the combined value of equity and debt, i.e, the firm value). Because of limited liability, managers have some flexibility in choosing a default policy that maximizes equity value. Operationally, we assume that the equityholder-managers can choose to cover the firm's operating losses by providing their own capital. Bankruptcy occurs when equity holders decide to stop injecting additional capital. They do this by selecting a bankruptcy trigger level $P_{b}$ so as to maximize the value of equity by declaring bankruptcy the first time $P_{t} \leq P_{b}$ after adoption of the second plant. We assume that in bankruptcy, debtholders receive their share of tangible assets with the value of $2 \gamma$ and shareholders receive the rest. Given the assumption that debt is risky (i.e., the debtholders may not be able to recover the whole amount of $c / r$ ), equity holders will receive zero. Under these assumptions, for each coupon level $c$, the equityholdermanager's value function is

$$
V_{2}(p, c):=\sup _{\tau \in \mathcal{S}} \mathbb{E}^{p}\left[\int_{0}^{\tau} e^{-r s}\left(2 P_{s}-2 \xi-(1-\theta) c\right) \mathrm{d} s\right]
$$


where $\mathbb{E}^{p}[\cdot]$ is expectation under the probability law with $P_{0}=p$ and $\mathcal{S}$ is a set of $\mathcal{F}_{t}^{P}$ (the natural filtration generated by process $P$ ) stopping times. $\theta$ is a corporate tax rate with $0 \leq \theta \leq 1$ so that $c \theta$ is the tax shield on debt. This formulation is similar to the example in Chapter 11 of Duffie [10]. Equation (2.2) indicates that, for a given debt level of $c / r$, the managers will choose the bankruptcy threshold in order to maximize equity value. This problem has an explicit solution. Consider the infinitesimal generator $\mathcal{A}$ of $P: \mathcal{A} u(p) \triangleq\left(\sigma^{2} / 2\right) p^{2} u^{\prime \prime}(p)+\mu p u^{\prime}(p)$ acting on a smooth function $u(\cdot)$. The o.d.e. $(\mathcal{A}-r) u(p)=0$ provides the fundamental solutions $\psi(p) \triangleq p^{\lambda_{1}}$ and $\varphi(p) \triangleq p^{\lambda_{2}}$ with $\lambda_{1}>1$ and $\lambda_{2}<0$, which are the two roots of $\lambda(\lambda-1) \sigma^{2} / 2+\lambda \mu-r=0$ and play an important role in the analysis. Denote $\lambda:=\min \left(\lambda_{1}, \lambda_{2}\right)=\lambda_{2}$ when there is no risk of ambiguity.

Proposition 2.1. For a given contractual coupon level $c$, the bankruptcy level $P_{b}(c)$ is given by

$$
P_{b}(c)=-\frac{\lambda}{1-\lambda} \frac{(2 \xi+(1-\theta) c)(r-\mu)}{2 r}
$$

and the equity value on $\left(P_{b}(c), \infty\right)$ and debt value on $\left(P_{b}(c), \infty\right)$ are

$$
V_{2}(p, c)=\frac{2 p}{r-\mu}-\frac{2 \xi+(1-\theta) c}{r}-\left(\frac{2 P_{b}(c)}{r-\mu}-\frac{2 \xi+(1-\theta) c}{r}\right)\left(\frac{p}{P_{b}(c)}\right)^{\lambda},
$$

and

$$
D(p, c)=\frac{c}{r}+\left(2 \gamma-\frac{c}{r}\right)\left(\frac{p}{P_{b}(c)}\right)^{\lambda}
$$

respectively. On $p \in\left(0, P_{b}(c)\right)$, we have $V_{2}(p, c)=0$ and $D(p, c)=2 \gamma$.

Now let us go back to the original firm that owns one plant with an option to invest in an identical plant at cost $I$. Investment can be made at any time and, if made, is financed by perpetual debt with principal $c / r$. For each coupon rate level $c$, managers wish to maximize equity value, $V_{1}(p, c)$, of the firm by solving the following two-boundary optimal stopping problem for each $c$,

$$
V_{1}(p, c):=\sup _{\tau_{m}, \tau_{d} \in \mathcal{S}} \mathbb{E}^{p}\left[\int_{0}^{\tau_{m} \wedge \tau_{d}} e^{-r s}\left(P_{s}-\xi\right) \mathrm{d} s+e^{-r \tau_{m}} \gamma 1_{\left\{\tau_{m}<\tau_{d}\right\}}+e^{-r \tau_{d}} V_{2}\left(P_{\tau_{d}}, c\right) 1_{\left\{\tau_{m}>\tau_{d}\right\}}\right] .
$$

In other words, if the output price $P$ reaches some value $P_{m}(c)$ before it reaches $P_{d}(c)$, managers will close the current plant and collect scrap value $\gamma$. Otherwise, they will build a new plant at cost $I$ when time $\tau_{d}$ comes. In this event, the original firm borrows an amount of debt $c / r$. This one-plant firm, thereby, becomes the firm whose equity value should be equal to $V_{2}\left(P_{d}, c\right)$ in Equation (2.4). The optimal threshold values $P_{m}$ and $P_{d}$ maximize equity value. One may be tempted here to conclude $I=\frac{c}{r}$. However, it is important to recall that $I$ is debt value at the time of investment. See Equation (2.7).

Proposition 2.2. If we have $r>\mu$ and $c(1-\theta) / r>2 \gamma$, there exists an interval $\left(P_{m}(c), P_{d}(c)\right) \in \mathbb{R}_{+}$, for given $c \in \mathbb{R}_{+}$such that $\tau_{m}^{*}=\left\{t \geq 0: P_{t} \leq P_{m}(c)\right\}$ and $\tau_{d}^{*}=\left\{t \geq 0: P_{t} \geq P_{d}(c)\right\}$ are optimal closing and investment times, respectively, for (2.6). The value function to problem (2.6) is continuous in $\mathbb{R}_{+}$and is of the form

$$
V_{1}(p, c)= \begin{cases}\gamma, & p \leq P_{m}(c), \\ B_{1}(c) p^{\lambda_{1}}+B_{2}(c) p^{\lambda_{2}}+\frac{p}{r-\mu}-\frac{\xi}{r}, & P_{m}(c)<p<P_{d}(c), \\ V_{2}(p, c), & P_{d}(c) \leq p,\end{cases}
$$

where $B_{1}(c)$ and $B_{2}(c)$ along with $P_{m}(c)$, and $P_{d}(c)$ are uniquely determined. The computation for these values is described in Section 5.2 with the proof of this proposition. 
Note that $V_{1}(p, c)$ depends on the debt level $c \in \mathbb{R}_{+}$(a family of functions parameterized by $c$ ). Appropriate accounting of bankruptcy risk requires equating investment cost $I$ with debt value at the investment threshold (see, for example, Mella-Barrel and Perraudin [19]). Since the value of the debt $D(p, c)$ is given by $(2.5)$, this requirement is written as

$$
I=\frac{c}{r}+\left(2 \gamma-\frac{c}{r}\right)\left(\frac{P_{d}(c)}{P_{b}(c)}\right)^{\lambda} .
$$

Thus, among $P_{d}(c)$ (that solve the optimal stopping problem (2.6) for a given $c$ ), we find $c=\bar{c}$ that also satisfies (2.7). That is, for this level $\bar{c},(2.6)$ and (2.7) are simultaneously solved and we obtain $P_{m}(\bar{c})$ and $P_{d}(\bar{c})$ along with $V_{1}(p):=V_{1}(p, \bar{c})$.

Remark 2.1. When the debt principal, $c / r$, is less than the salvage value of assets, $2 \gamma$, bankruptcy does not occur. Timing of firm closure is then efficient, leverage imposes no agency costs, and the value of the firm is the same as it would be under pure equity financing. Since debt would be free of risk, the firm is effectively operated as an all-equity interest. Equity value is given by

$$
V_{1}(p)=U_{1}(p) \quad \text { and } \quad V_{2}(p, c)=U_{2}(p)-D(p, c)
$$

where debt value $D(p, c)=I$. Conversely, whenever $c(1-\theta) / r>2 \gamma$ as in Proposition 2.2, debt is risky.

\subsection{Equity Financing}

To complete our model formulation, we now turn to investment under pure equity financing. If profits are too low, the firm could be shut down before there is a chance to invest in the second plant. The firm owns several real options in the form of liquidation and plant expansion and exercises them such that equity value is maximized. Let $U_{2}$ denote the value of the pure equity firm that already owns two plants and has an income flow $2 P_{t}-2 \xi$. Firm value is contingent on output price. The pure equity firm's problem is to find an optimal closure policy $\tau$,

$$
U_{2}(p):=\sup _{\tau \in \mathcal{S}} \mathbb{E}^{p}\left[\int_{0}^{\tau} e^{-r s}\left(2 P_{s}-2 \xi\right) \mathrm{d} s+e^{-r \tau} 2 \gamma\right] .
$$

At closure, the total value of firm assets must equal salvage value $2 \gamma$.

Proposition 2.3. The closure level $P_{c}$ is obtained by $P_{c}=-\frac{\lambda}{1-\lambda} \frac{(\xi+r \gamma)(r-\mu)}{r}$ and the value of the pure equity firm with two plants is

$$
U_{2}(p)=\frac{2 p}{r-\mu}-\frac{2 \xi}{r}+2\left(\gamma-\frac{P_{c}}{r-\mu}+\frac{\xi}{r}\right)\left(\frac{p}{P_{c}}\right)^{\lambda},
$$

on $\left[P_{c}, \infty\right)$ and $U_{2}(p)=2 \gamma$ on $\left(0, P_{c}\right)$.

Proof. The proof is similar to that of Proposition 2.1 and is omitted.

Next, let us consider a firm that owns one plant and an option to invest in an identical plant at cost $I$. This time we assume the investment is entirely financed by equity. The value of this firm, denoted $U_{1}$, is the solution to the optimal stopping problem

$$
U_{1}(p):=\sup _{\tau_{l}, \tau_{e} \in \mathcal{S}} \mathbb{E}^{p}\left[\int_{0}^{\tau_{l} \wedge \tau_{e}} e^{-r s}\left(P_{s}-\xi\right) \mathrm{d} s+e^{-r \tau_{l}} \gamma 1_{\left\{\tau_{l}<\tau_{e}\right\}}+e^{-r \tau_{e}}\left(U_{2}\left(P_{\tau_{e}}\right)-I\right) 1_{\left\{\tau_{l}>\tau_{e}\right\}}\right] .
$$


In other words, if the output price $P$ reaches some value $P_{l}$ before it reaches $P_{e}$, the equityholdermanager will close the current plant and receive $\gamma$. Otherwise, the managers will build a new plant at cost $I$. The proof of the following assertion is similar to Proposition 2.2 and is omitted.

Proposition 2.4. If $r>\mu$, there exists an interval $\left(P_{l}, P_{e}\right) \in \mathbb{R}_{+}$such that $\tau_{l}^{*}=\inf \left\{t \geq 0: P_{t} \leq P_{l}\right\}$ and $\tau_{e}^{*}=\inf \left\{t \geq 0: P_{t} \geq P_{e}\right\}$ are optimal closing and investment times, respectively. The value function of the problem (2.10) is

$$
U_{1}(p)= \begin{cases}\gamma, & p \leq P_{l} \\ A_{1} p^{\lambda_{1}}+A_{2} p^{\lambda_{2}}+\frac{p}{r-\mu}-\frac{\xi}{r}, & P_{l}<p<P_{e} \\ U_{2}(p)-I, & P_{e} \leq p\end{cases}
$$

where $A_{1}$ and $A_{2}$ along with $P_{l}$ and $P_{e}$ are uniquely determined.

\subsection{Value of Loan Commitments and Agency Cost}

One can argue that, due to the existence of tax shield on debt, for each initial price level $p, \max \left(0, V_{1}(p)-\right.$ $\left.U_{1}(p)\right)$ represents the value of the loan commitment equity holder received from the lender. This must be so since without the loan commitment, equityholder-manager has no other ways to finance the planned expansion except through equity financing (see Section 4 for the case of mixed debt and equity funding). This value is mainly due to the tax shield but it partially derives from an added expense to the lender, as discussed in the next paragraph.

As presented later in Table 1, the tax shield makes debt financing more attractive and prompts overinvestment. The lender could claim that a part of the value created by the loan commitment is at its expense and, therefore, it is entitled to a share of the benefit that the equityholder receives. One way to quantify this compensation is as follows. As argued in the literature, since the rational debtholder will value debt under the assumption that equityholders will exercise the option to maximize equity value, debt will be priced as in Section 2.1 (by solving Equations (2.6) and (2.7)). In return, the debtholder could argue that some value is lost due to the manager's action of maximizing equity value instead of firm value. If the manager were to maximize firm value, the corresponding optimal stopping problem would be

$$
\begin{aligned}
\bar{V}_{1}(p):=\sup _{\tau_{m}, \tau_{d} \in \mathcal{S}} \mathbb{E}^{p}\left[\int_{0}^{\tau_{m} \wedge \tau_{d}} e^{-r s}\left(P_{s}-\xi\right) \mathrm{d} s\right. \\
\left.\quad+e^{-r \tau_{m}} \gamma 1_{\left\{\tau_{m}<\tau_{d}\right\}}+e^{-r \tau_{d}}\left\{V_{2}\left(P_{\tau_{d}}, \bar{c}\right)+D\left(P_{\tau_{d}}, \bar{c}\right)-I\right\} 1_{\left\{\tau_{m}>\tau_{d}\right\}}\right],
\end{aligned}
$$

given debt is priced at $\bar{c}$ as in Section 2.1. Equation (2.11) yields the liquidation and investment threshold levels $P_{\bar{m}}$ and $P_{\bar{d}}$, respectively. We claim the following proposition must hold.

Proposition 2.5. Suppose $r>\mu$ and $c(1-\theta) / r>2 \gamma$. For value functions $V_{1}(p)=V_{1}(p, \bar{c})$ in $(2.6)$ and $\bar{V}_{1}(p)$ in (2.11), we have $V_{1}(p) \leq \bar{V}_{1}(p)$ for $p \in \mathbb{R}_{+}$.

Consequently, the lender may argue that, for any $p \in \mathbb{R}_{+}$,

$$
\left(\bar{V}_{1}(p)-U_{1}(p)\right)-\left(V_{1}(p)-U_{1}(p)\right)=\bar{V}_{1}(p)-V_{1}(p)>0
$$

represents the agency cost that is incurred since the first term on the right hand side is the value of having the loan commitment that could have been added if managers maximized firm value. 


\subsection{Positive Construction Period}

We further consider a more realistic case when the construction of the second plant requires certain period of time $\Delta>0$. For the purpose of simplicity and comparison with the preceding analysis, we assume that the construction period is constant and the equityholder seeks an optimal threshold strategy as in previous sections. As a result of this non-zero construction period, the original problem becomes

$$
\begin{aligned}
V_{1}^{\Delta}(p, c):=\sup _{\tau_{m}, \tau_{d} \in \mathcal{S}} & \mathbb{E}^{p}\left[\int_{0}^{\tau_{m} \wedge\left(\tau_{d}+\Delta\right)} e^{-r s}\left(P_{s}-\xi\right) \mathrm{d} s\right. \\
& \left.+e^{-r \tau_{m}} \gamma 1_{\left\{\tau_{m}<\tau_{d}+\Delta\right\}}+e^{-r \tau_{d}} V_{2}\left(P_{\tau_{d}+\Delta}, c\right) 1_{\left\{\tau_{m}>\tau_{d}+\Delta\right\}}\right],
\end{aligned}
$$

where $\tau_{d}$ is the time when the equityholder decides to exercise the expansion option and start the construction. Note that the new plant is available for production at time $\tau_{d}+\Delta$. Let us denote the optimal time to start the construction by $\tau_{d^{\Delta}}$ and the price of the product at that time by $P_{d^{\Delta}}$. It is reasonable to assume the following:

Assumption 2.1. (a) The debt is priced at time $\tau_{d}^{\Delta}$ with $P_{d}(c)=P_{d^{\Delta}}(c)$ in (2.7).

(b) Once the construction begins, the construction must be completed and thereby the equityholder is not allowed to declare bankruptcy (until completion).

As to the first assumption, this is because the bank does not run the risk of unknown price level at time $\tau_{d}^{\Delta}+\Delta$. Then the debt is issued at time $\tau_{d}^{\Delta}+\Delta$ and the construction cost $I$ is paid simultaneously. The second assumption also makes sense because the lender protects their interest and avoids the manager (equityholder) throwing away the new plant under construction. As we see below in the numerical experiments with typical parameters, this leads to a reduction of the value of the loan commitment and agency cost. Our assumptions above pertain to contract/negotiation matters about which party assumes costs involved in additional uncertainty.

Now to study the agency cost in this case, we need the counterparts of (2.10) and (2.11), which are

$$
\begin{aligned}
U_{1}^{\Delta}(p):=\sup _{\tau_{l}, \tau_{e} \in \mathcal{S}} \mathbb{E}^{p}\left[\int_{0}^{\tau_{l} \wedge\left(\tau_{e}+\Delta\right)} e^{-r s}\left(P_{s}-\xi\right) \mathrm{d} s\right. \\
\left.+e^{-r \tau_{l}} \gamma 1_{\left\{\tau_{l}<\tau_{e}+\Delta\right\}}+e^{-r\left(\tau_{e}+\Delta\right)}\left(U_{2}\left(P_{\tau_{e}+\Delta}\right)-I\right) 1_{\left\{\tau_{l}>\tau_{e}+\Delta\right\}}\right],
\end{aligned}
$$

and

$$
\begin{aligned}
\bar{V}_{1}^{\Delta}(p):=\sup _{\tau_{m}, \tau_{d} \in \mathcal{S}} \mathbb{E}^{p}\left[\int_{0}^{\tau_{m} \wedge\left(\tau_{d}+\Delta\right)} e^{-r s}\left(P_{s}-\xi\right) \mathrm{d} s+e^{-r \tau_{m}} \gamma 1_{\left\{\tau_{m}<\tau_{d}+\Delta\right\}}\right. \\
\left.+e^{-r\left(\tau_{d}+\Delta\right)}\left\{V_{2}\left(P_{\tau_{d}+\Delta}, \bar{c}\right)+D\left(P_{\tau_{d}+\Delta}, \bar{c}\right)-I\right\} 1_{\left\{\tau_{m}>\tau_{d}+\Delta\right\}}\right],
\end{aligned}
$$

respectively. While the value functions become very complex, these problems are still tractable. See Section 5.4 for computations of the solution.

\section{Results}

In this numerical example, first, let us look at the overinvestment/underinvestment issue. ${ }^{3}$ We can single out the role of bankruptcy risk by comparing the investment threshold $P_{d}$ (under threat of bankruptcy)

\footnotetext{
${ }^{3}$ The comparison here is, in terms of Case (A), (B) and (C) in the introduction section, between (A) and (C).
} 
Table 1: Investment thresholds $P_{e}$ and $P_{d}$ for an investment cost $I=30$

\begin{tabular}{c|c|ccc|ccc|c}
\hline & & $\theta=0$ & & & $\theta=0.3$ & & \multicolumn{3}{l}{} \\
\hline$\sigma$ & $P_{e}$ & $P_{d}$ & $\frac{P_{e}-P_{d}}{P_{d}} \%$ & $\bar{c}$ & $P_{d}$ & $\frac{P_{e}-P_{d}}{P_{d}} \%$ & $\bar{c}$ & $P_{\bar{d}}$ \\
\hline \hline 0.01 & 1.55 & 1.55 & 0.00 & 1.20 & & & & \\
0.05 & 1.77 & 1.78 & -0.28 & 1.36 & 1.30 & 36.16 & 1.36 & 1.31 \\
0.10 & 2.09 & 2.11 & -1.14 & 1.40 & 1.54 & 35.71 & 1.41 & 1.59 \\
0.15 & 2.46 & 2.49 & -1.31 & 1.47 & 1.81 & 35.91 & 1.48 & 1.92 \\
0.20 & 2.88 & 2.90 & -0.95 & 1.54 & 2.11 & 36.50 & 1.55 & 2.29 \\
0.25 & 3.35 & 3.36 & -0.36 & 1.63 & 2.44 & 37.30 & 1.64 & 2.69 \\
0.30 & 3.87 & 3.86 & 0.27 & 1.72 & 2.80 & 38.21 & 1.73 & 3.14 \\
0.35 & 4.45 & 4.42 & 0.86 & 1.82 & 3.20 & 39.06 & 1.83 & 3.63 \\
0.40 & 5.09 & 5.03 & 1.37 & 1.93 & 3.63 & 40.22 & 1.94 & 4.17 \\
\hline$P_{e}$
\end{tabular}

$P_{e}$ and $P_{d}$ are investment threshold levels for equity, and debt financed investments, respectively. The firm invests in the additional plant as soon as output price reaches the corresponding investment threshold level. The last column $P_{\bar{d}}$ is the investment threshold if the firm maximized the entire firm value rather than the equity value.

and $P_{e}$ (without bankruptcy risk). To do so, we change price volatility, holding other parameters constant. Specifically, let $\sigma$ vary from 10 percent to 40 percent and fix other parameters as follows: a salvage value, $\gamma$, of 2 , a risk-free interest rate of 4.5 percent, and a flow $\operatorname{cost} \xi=0.15$. Finally, we set $\mu=0$ and $I=30$.

Let us first examine the case with corporate tax rate $\theta=0$ to obtain insight into pure effect of the bankruptcy threat. Table 1 shows values of investment thresholds for various price volatilities. All values of investment thresholds are higher than $\xi+r I(=1.5)$, the full cost of investing and operating the additional plant (Dixit [8]). This is due to the effect of profit uncertainty on the investment option. In addition, investment thresholds increase as volatility increases. This is consistent with the general finding in real options literature that the higher the uncertainty, the higher the investment threshold (McDonald and Siegel [18] and Dixit and Pindyck [9]). Comparing the trigger prices for adopting the second plant with and without the risk of bankruptcy, we find that, when volatility is low, $P_{e}<P_{d}$. There is a crossover level where the investment threshold for debt financing starts lower than the equity financing threshold as $\sigma$ increases (around $\sigma=0.275$ in this example). As $\sigma$ increases, the negative gap between $P_{e}$ and $P_{d}$ reaches an apex before narrowing to zero and changing sign. The percentage difference in investment thresholds between the debt and equity financing is illustrated in Figure 1. It implies that the prospect of bankruptcy distorts real investment decisions in a direction that depends on the level of volatility. ${ }^{4}$ Investment threshold levels for equity and debt financing are compared in the center picture of Figure 1 for different interest rate and production cost scenarios. An even more interesting picture emerges when the amount of financing is considered. The graph on the right shows that a levered firm may be either more or less likely to make an irreversible investment than a pure equity firm depending on the level of uncertainty and the amount of capital at risk (project size minus salvage value, or market-tobook value of the firm). The combination of these two factors determines whether debt induces early or late investment compared with equity financing. It is interesting that early investments diminish in very highly volatile environments.

Next, we examine the case with tax rate $\theta=0.3$ in Table 1 . In the presence of the tax shield, the situation is very different. For all levels of volatility, we observe overinvestment phenomena with $P_{d}$ being substantially smaller than $P_{e}$. As expected, the tax shield makes debt financing more attractive and

\footnotetext{
${ }^{4}$ In contrast, $P_{e}>P_{d-}$ as long as debt is risky, where price $P_{d-}$ is the threshold level assuming debt financing treats the project as risk-free, corresponding to overinvestment in all cases. This is to be expected since bankruptcy risk is undervalued in obtaining $P_{d-}$.
} 


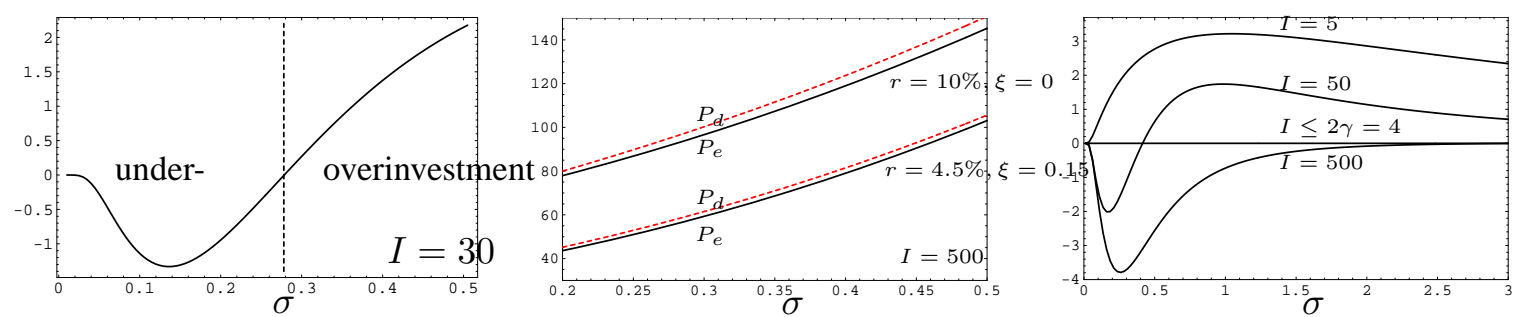

Figure 1: Investment threshold levels. Left: Percentage difference $\left(\frac{P_{e}-P_{d}}{P_{d}} \times 100\right)$ between equity and debt financed investment thresholds for $I=30$ as a function of price volatility $(\sigma)$. Center: It compares investment threshold levels $P_{e}$ and $P_{d}$ under equity and debt financing, respectively. Right: compares the percentage difference between equity and debt financed investment thresholds for small and large capital requirements. When the investment amount does not exceed salvage value of assets (i.e., $I \leq 4)$, debt and equity financing are interchangeable. All curves approach zero for sufficiently high price volatilities.

prompts the managers to exercise the expansion option early. It is worth noting that while the coupon levels $\bar{c}$ in this case are higher as compared to the case $\theta=0$, the differences are very small across all volatility levels. This implies that debt value does not increase much. We now focus on the closely related issue, namely the value of the loan commitment that equityholder obtained from the lender in the presence of tax shields. Figure 2 illustrates the relationship of the three value functions, $V_{1}, U_{1}$, and $\bar{V}_{1}$. The first graph (a) shows the equity value $V_{1}$. In graph (b), we see that $V_{1}>U_{1}$ and the vertical distance (= the value of the loan commitment) is plotted in graph (c). To compute the agency cost involved here, we find $\bar{V}_{1}$, the value function of firm value maximization problem. The threshold levels $\left(P_{\bar{m}}, P_{\bar{d}}\right)=(0.100615,2.68965)$. We confirm that $\left(P_{\bar{m}}, P_{\bar{d}}\right) \supset\left(P_{m}, P_{d}\right)=(0.100661,2.43567)$ so that the equity value maximization policy tends to overinvestment (as compared to firm value maximization) ${ }^{5}$. The agency cost associated (defined by $\bar{V}_{1}-V_{1}$ ) is plotted in graph (d). In this particular example, the relative size of the agency cost to the value of the loan commitment is small.

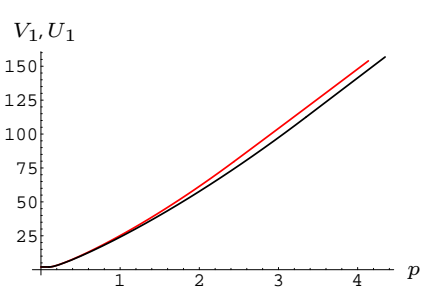

(a)

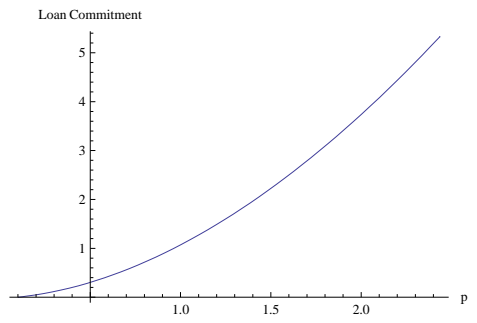

(b)

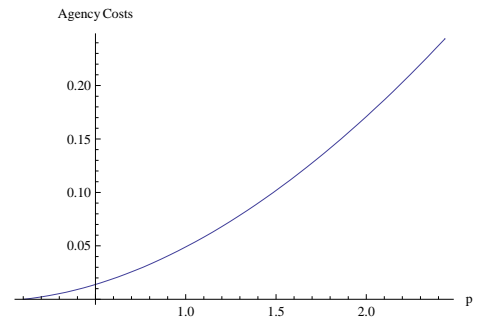

(c)

Figure 2: The value functions: With $\sigma=0.25$ and $\theta=0.3$, (a) the value function of the equity financing $U_{1}(p)$ situated below the $V_{1}$ function, (b) the vertical distance between the two curves represents the value of the loan commitment and (c) the agency costs represented by $\bar{V}_{1}(p)-V_{1}(p)$.

Now let us raise the uncertainty level $\sigma$ from 0.25 to 0.4 to see how the loan commitment value and the agency costs will change. Note first that we observe again the consistent result: $(0.05883,3.6333)=$ $\left(P_{m}, P_{d}\right) \subset\left(P_{\bar{m}}, P_{\bar{d}}\right)=(0.05878,4.16677)$. With the higher volatility, the value of the loan commitment increases across almost all the price levels. See Figure 3-(a). This is consistent with the general belief that the borrower takes advantage of higher volatility via debt financing. The problem of agency

\footnotetext{
${ }^{5}$ This comparison here is, in terms of Case (A), (B) and (C) in the introduction section, between (A) and (B).
} 


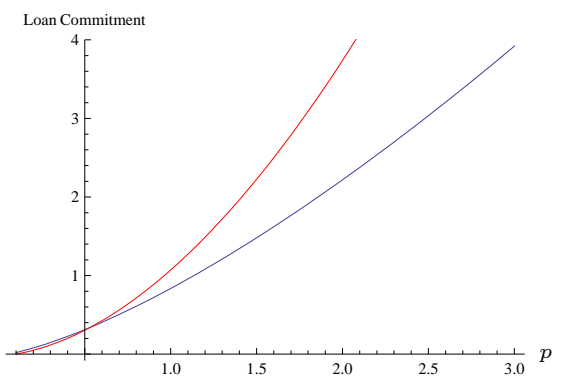

(a)

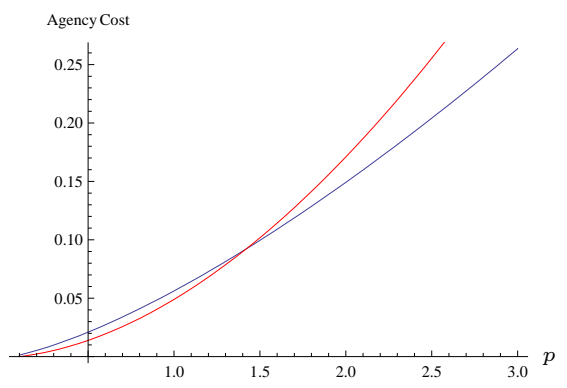

(b)

Figure 3: Comparative statics: We raised the uncertainty level $\sigma$ from 0.25 to 0.4 . (a) The above (red) curve represents the value of the loan commitment corresponding to $\sigma=0.40$ which is greater than that corresponding to $\sigma=0.25$ for all initial price level. (b) The agency cost is not straightforward. For lower output prices, the agency cost is higher with the lower volatility level $(\sigma=0.25)$. This is reversed in the higher output price range.

costs is more interesting. As seen form Figure 3-(b), in low initial prices, the agency cost incurred on the lender is greater when the volatility level is lower $(\sigma=0.25)$. This relationship is reversed in higher price levels. Since the agency cost is defined via (2.11) and (2.12), a possible explanation is as follows: When the output price is low (around $p=1.0$ ), the value of the debt $D(p, \bar{c})$ is low as well and should be aggravated (i.e., greater risk of default) by the higher volatility $(\sigma=0.4)$. Hence the $\bar{V}_{1}$ value tends to be lower and accordingly the agency cost $\left(=\bar{V}_{1}-V_{1}\right)$ results in lower levels in this price range.

Figure 4 displays the effect of construction period on the value functions. First, graph (a) shows that the value of the equity drops from $V_{1}(x)$ to $V_{1}^{\Delta}$ as expected. Graph 4-(b) shows that the value of loan commitment obtained by the equityholder (from the lender), which is $V_{1}^{\Delta}-U_{1}^{\Delta}$ does not change much from the original $V_{1}-U_{1}$. Since

$$
\left(V_{1}-U_{1}\right)-\left(V_{1}^{\Delta}-U_{1}^{\Delta}\right)=\left(V_{1}-V_{1}^{\Delta}\right)-\left(U_{1}-U_{1}^{\Delta}\right)
$$

this means that the drop of the value (due to the delay) is not significantly different between debt financing and equity financing. It is understandable since the delay risk affects the equity value almost equally in debt and equity financing (i.e., $V_{1}-V_{1}^{\Delta} \simeq U_{1}-U_{1}^{\Delta}$ ). The amount of agency cost with positive construction period, $\bar{V}_{1}^{\Delta}-V_{1}^{\Delta}$ is also smaller than the original $\bar{V}_{1}-V_{1}$ (see graph (c)). The mechanism is rather complicated: We note first that

$$
\left(\bar{V}_{1}-V_{1}\right)-\left(\bar{V}_{1}^{\Delta}-V_{1}^{\Delta}\right)>0 \Leftrightarrow\left(V_{1}-V_{1}^{\Delta}\right)-\left(\bar{V}_{1}-\bar{V}_{1}^{\Delta}\right)<0 .
$$

The last inequality shows that the drop in the value of $\bar{V}_{1}$ (firm value maximization) is greater than that of $V_{1}$ in the presence of delay. It is partly because that the debt value is also hit by the increased uncertainty. As a consequence of this effect, the agency cost incurred on the lender's side shrinks.

Finally, we examine the case of positive construction period with $\sigma=0.4$ (Figure 5). The difference between $V_{1}$ and $V_{1}^{\Delta}$ is greater in this case, reflecting that the increased uncertainty caused by a higher volatility (graph (a)) further reduces the equity value. In graph (c), we can see the vertical distances between two lines become wider. This means that a larger volatility coupled with positive construction period further reduces the agency costs from the original value. 


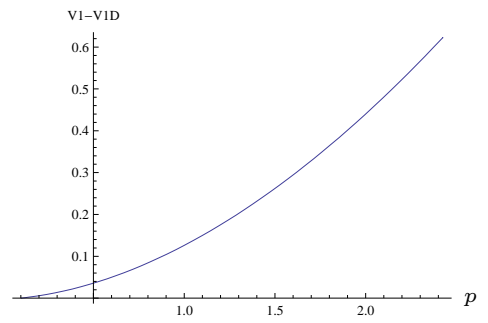

(a)

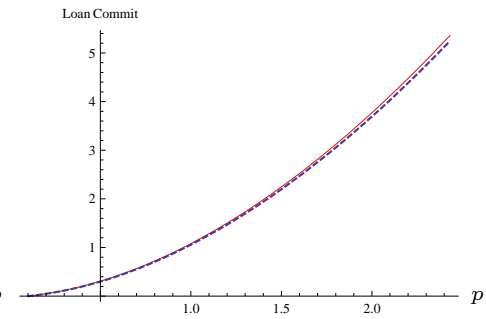

(b)

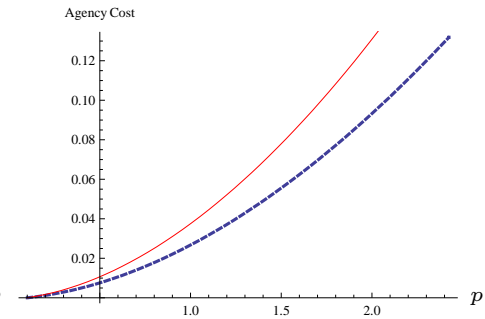

(c)

Figure 4: The value functions with positive construction period in expansion $(\sigma=0.25)$. With $\sigma=0.25, \theta=0.3$ and $\Delta=0.5$, (a) $V_{1}(p)-V_{1}^{\Delta}(p)$ is plotted for each $p$. The continuation region shifts shrinks from the original $(0.10066,2.43567)$ to $(0.100771,2.42461)$ with $\Delta=0.5$. (b) the value of the loan commitment $V_{1}^{\Delta}-U_{1}^{\Delta}$ (below, blue dashed) does not change much from the original level $V_{1}-U_{1}$ (above, red solid). (c) the agency costs $\bar{V}_{1}^{\Delta}-V_{1}^{\Delta}$ decreased (below, blue dashed) from the original $\bar{V}_{1}-V_{1}$ (above, red solid).

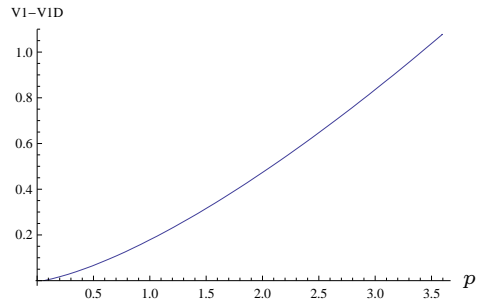

(a)

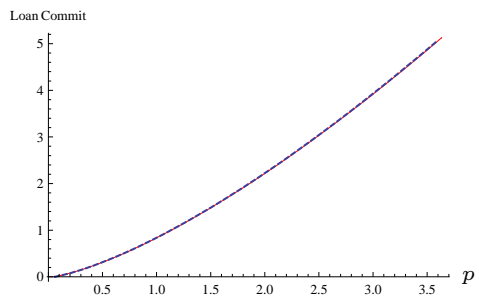

(b)

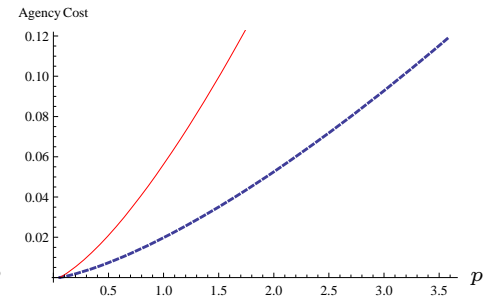

(c)

Figure 5: The value functions with positive construction period in expansion $(\sigma=0.40)$. With $\sigma=$ 0.40 and $\theta=0.3$, (a) $V_{1}(p)-V_{1}^{\Delta}(p)$ is plotted for each $p$. The continuation region shrinks from $(0.05883,3.6333)$ to $(0.058993,3.59528)$. (b) the value of the loan commitment $V_{1}^{\Delta}-U_{1}^{\Delta}$ (below, blue dashed) does not change much from the original value $V_{1}-U_{1}$ (above, red solid). (c) the agency costs $\bar{V}_{1}^{\Delta}-V_{1}^{\Delta}$ decreased (below, blue dashed) from the original $\bar{V}_{1}-V_{1}$ (above, red solid).

\section{Concluding Remarks}

Our model can be extended in several ways. First, the debt-equity ratio can be considered in our model. Suppose that the lender commits to provide only partial financing of the investment cost $I$ so that the investment cost can be split into a debt financed part $I_{d}$ and an equity financed part $I_{e}$. Equations (2.6) and (2.7) become

$$
\tilde{V}_{1}(p, c) \triangleq \sup _{\tau_{m}, \tau_{d} \in \mathcal{S}} \mathbb{E}^{p}\left[\int_{0}^{\tau_{m} \wedge \tau_{d}} e^{-r s}\left(P_{s}-\xi\right) \mathrm{d} s+e^{-r \tau_{m}} \gamma 1_{\left\{\tau_{m}<\tau_{d}\right\}}+e^{-r \tau_{d}}\left\{V_{2}\left(P_{\tau_{d}}, \bar{c}\right)-I_{e}\right\} 1_{\left\{\tau_{m}>\tau_{d}\right\}}\right],
$$

and

$$
I_{d}=\frac{c}{r}+\left(2 \gamma-\frac{c}{r}\right)\left(\frac{P_{d}(c)}{P_{b}(c)}\right)^{\lambda},
$$

respectively. Hence one can find the threshold levels for any combinations of $I_{d}$ and $I_{e}$. Alternatively, for a given coupon level $c$, one can compute the investment threshold level $P_{d}(c)$ and $I_{d}$ that satisfy both Equations (4.1) and (4.2) and find the optimal debt level subject to a desired condition, for example, maximizing firm value at a certain level of $p$. 
We have assumed that default leads to liquidation of firm assets. In practice, a financially distressed firm may either liquidate its assets or decide to renegotiate its debt obligations. Including this possibility in the analysis will affect investment decisions. In addition, policy distortions may be even greater if conflicts of interest between managers and shareholders of the firm are taken into account. Choice of debt maturity is yet another variable that firm managers can use to increase equity value at the expense of firm value. In case of positive construction period, we could make other assumptions regarding which party assumes the risk involved in additional uncertainties (cf. Assumption 2.1). We note that our Assumption 2.1 is reasonable in light of real business conventions and leads to a mathematically tractable formulation.

\section{Appendix}

\subsection{Proof of Proposition 2.1}

Consider the performance measure $J: \mathbb{R}_{+} \times \mathbb{R}_{+} \rightarrow \mathbb{R}$ where $J(p, c) \triangleq \mathbb{E}^{p}\left[\int_{0}^{\tau} e^{-r s}\left(2 P_{s}-2 \xi-(1-\theta) c\right) \mathrm{d} s\right]$ and use the strong Markov property of $P$,

$$
\begin{aligned}
J(p, c) & =\mathbb{E}^{p}\left[\int_{0}^{\infty} e^{-r s}\left(2 P_{s}-2 \xi-(1-\theta) c\right) \mathrm{d} s-\int_{\tau}^{\infty} e^{-r s}\left(2 P_{s}-2 \xi-(1-\theta) c\right) \mathrm{d} s\right] \\
& =\frac{2 p}{r-\mu}-\frac{(2 \xi+(1-\theta) c)}{r}-\mathbb{E}^{p}\left[e^{-r \tau} \mathbb{E}^{X_{\tau}}\left[\int_{0}^{\infty} e^{-r s}\left(2 P_{s}-2 \xi-(1-\theta) c\right) \mathrm{d} s\right]\right] \\
& =\frac{2 p}{r-\mu}-\frac{(2 \xi+(1-\theta) c)}{r}+\mathbb{E}^{p}\left[-e^{r \tau}\left(\frac{2 P_{\tau}}{r-\mu}-\frac{(2 \xi+(1-\theta) c)}{r}\right)\right] .
\end{aligned}
$$

Since the first term is independent of $\tau$, we consider only the second term to maximize over all the possible $\tau \in \mathcal{S}$. This is a straightforward problem and can be solved by the usual variational arguments. In the continuation region, the value function has the form with some $A(c) \in \mathbb{R}, V_{2}(p, c)=A(c) p^{\lambda}$ for a given $c$. By the first method, we can easily verify that, at the boundary $P_{b}(c)$, the smooth-fit principle works. The optimal stopping policy is $\tau^{*}=\inf \left\{t \geq 0: P_{t} \leq P_{b}(c)\right\}$.

On the other hand, the debt value can be calculated, again with the strong Markov property,

$$
D(p, c)=\mathbb{E}^{p}\left[\int_{0}^{\tau} e^{-r s} c \mathrm{~d} s+e^{-r \tau} 2 \gamma\right]=\frac{c}{r}+\left(2 \gamma-\frac{c}{r}\right) \mathbb{E}^{p}\left[e^{-r \tau}\right]
$$

The last expectation is equal to $B p^{\lambda}$ for some $B \in \mathbb{R}$. Applying the boundary condition at $P_{b}(c)$, we have $1=B P_{b}(c)^{\lambda}$, which leads to our formula (2.5).

\subsection{Proof of Proposition 2.2}

Let us prove that for a given $c \in \mathbb{R}_{+}$that satisfies $c(1-\theta) / r>2 \gamma$, there exists a unique vector $\left(B_{1}(c), B_{2}(c), P_{m}(c), P_{d}(c)\right)$ as a solution to (2.6). Similar to the proof for Proposition 2.1, we use the strong Markov property of $P$ to obtain:

$$
\begin{aligned}
J_{1}(p, c) & :=\mathbb{E}^{p}\left[\int_{0}^{\tau_{m} \wedge \tau_{d}} e^{-r s}\left(P_{s}-\xi\right) \mathrm{d} s+e^{-r \tau_{m}} \gamma 1_{\left\{\tau_{m}<\tau_{d}\right\}}+e^{-r \tau_{d}} V_{2}\left(P_{\tau_{d}}, c\right) 1_{\left\{\tau_{m}>\tau_{d}\right\}}\right] \\
& =\mathbb{E}^{p}\left[e^{-r \tau_{m}} 1_{\left\{\tau_{m}<\tau_{d}\right\}}\left(\gamma-g\left(P_{\tau_{m}}\right)\right)+e^{-r \tau_{d}} 1_{\left\{\tau_{m}>\tau_{d}\right\}}\left(V_{2}\left(P_{\tau_{d}}, c\right)-g\left(P_{\tau_{d}}\right)\right)\right]+g(p)
\end{aligned}
$$


where $g(p):=\frac{p}{r-\mu}-\frac{\xi}{r}$. Since $g(p)$ is independent of optimal stopping rules, we shall find

$$
\bar{J}_{1}(p, c):=\sup _{\tau_{m}, \tau_{d} \in \mathcal{S}} \mathbb{E}^{p}\left[e^{-r \tau_{m}} 1_{\left\{\tau_{m}<\tau_{d}\right\}} f_{1}\left(P_{\tau_{m}}\right)+e^{-r \tau_{d}} 1_{\left\{\tau_{m}>\tau_{d}\right\}} f_{2}\left(P_{\tau_{d}}, c\right)\right]
$$

where $f_{1}(x):=\gamma-g(x)$ and $f_{2}(x, c):=V_{2}(x, c)-g(x)$.

Consider the infinitesimal generator $\mathcal{A}$ of the process $P: \mathcal{A} u(p):=\left(\sigma^{2} / 2\right) p^{2} u^{\prime \prime}(p)+\mu p u^{\prime}(p)$ acting on a smooth function $u(\cdot)$. The o.d.e. $(\mathcal{A}-r) u(p)=0$ will provide us the fundamental solutions $\psi(p):=p^{\lambda_{1}}$ and $\varphi(p):=p^{\lambda_{2}}$ with $\lambda_{1}>1$ and $\lambda_{2}<0$. Let us define an increasing function $F(p):=$ $\psi(p) / \varphi(p)$, more explicitly

$$
F(p)=p^{\lambda_{1}-\lambda_{2}} \quad \text { and } \quad F^{-1}(y)=y^{\frac{1}{\lambda_{1}-\lambda_{2}}} .
$$

Hence for each coupon level $c$, managers need to solve Equation (2.6) while satisfying condition (2.3). This is a two-sided optimal stopping problem where one has to find two threshold levels together with the value function. To proceed, we employ the characterization of the value function along the lines of Dynkin [11] and Dayanik and Karatzas [7]. Namely, if we find the smallest nonnegative concave majorant $W(y)$ of $H(y):=\max \left(H_{1}(y), H_{2}(y, c)\right)$ where $y \triangleq F(p)$, and

$$
H_{1}(y):=f_{1}\left(F^{-1}(y)\right) / \varphi\left(F^{-1}(y)\right) \quad \text { and } \quad H_{2}(y, c):=f_{2}\left(F^{-1}(y), c\right) / \varphi\left(F^{-1}(y)\right),
$$

then the value function $\bar{J}_{1}(p, c)$ can be obtained by $\bar{J}_{1}(p, c)=\varphi(p) W(F(p))$. Moreover, the optimal stopping region is given where $\{y: H(y)=W(y)\}$. Hence we find the points where $W$ and $H$ match for optimal threshold values. For the purpose of finding $W(y)$, we directly examine the function $H_{1}(y)$ and $H_{2}(y)$. We have $H_{1}(y)=\left(\gamma-\frac{1}{r-\mu} y^{\frac{1}{\lambda_{1}-\lambda_{2}}}+\frac{\xi}{r}\right) y^{\frac{-\lambda_{2}}{\lambda_{1}-\lambda_{2}}}$ and this function passes the origin, starts increasing (concave), takes the local maximum at point, say $y=y_{0}$ and decreases on $\left(y_{0}, \infty\right)$. It also becomes convex at point $y=y_{1}>y_{0}$.

On the other hand, recall that $V_{2}(p)$ function has two parts in $p \in\left[0, P_{b}(c)\right)$ and $p \in\left[P_{b}(c), \infty\right)$ and accordingly, $H_{2}(\cdot)$ is written, for any $c \geq 0$,

$$
H_{2}(y, c)= \begin{cases}-\frac{1}{r-\mu} y^{\frac{1-\lambda_{2}}{\lambda_{1}-\lambda_{2}}}+\frac{\xi}{r} y^{\frac{-\lambda_{2}}{\lambda_{1}-\lambda_{2}}}, & y \in\left[F(0), F\left(P_{b}(c)\right)\right], \\ \frac{1}{r-\mu} y^{\frac{1-\lambda_{2}}{\lambda_{1}-\lambda_{2}}}-\frac{\xi+(1-\theta) c}{r} y^{\frac{-\lambda_{2}}{\lambda_{1}-\lambda_{2}}}-K(c) \cdot\left(1 / P_{b}\right)^{\lambda_{2}}, & y \in\left[F\left(P_{b}(c)\right), \infty\right),\end{cases}
$$

where

$$
K(c):=\left(\frac{2 P_{b}(c)}{r-\mu}-\frac{2 \xi+(1-\theta) c}{r}\right)=-\frac{2 \xi+(1-\theta) c}{r(1-\lambda)}<0 .
$$

It is clear that $H_{2}(y, c)<H_{1}(y)$ on $y \in\left[F(0), F\left(P_{b}(c)\right)\right]$. Let us investigate the two functions in this region. The sole critical point $y_{0}$ of $H_{1}(y)$ is explicitly available: $p_{0}:=F^{-1}\left(y_{0}\right)=y_{0}^{\frac{1}{\lambda_{1}-\lambda_{2}}}=$ $-\frac{\lambda_{2}(r-\mu)\left(\gamma+\frac{\xi}{r}\right)}{1-\lambda_{2}}$. A simple algebra shows that if $c(1-\theta) / r>\gamma$, then $p_{0}<P_{b}(c)$. This implies the local maximum of $H_{1}(\cdot)$ is attained by $y_{0} \in\left[F(0), F\left(P_{b}(c)\right)\right]$ where we have $H_{1}(y)>H_{2}(y, c)$.

Let us look into the other region, $y \in\left(F\left(P_{b}(c)\right), \infty\right)$. The second branch of $H_{2}(y)$ starts with decreasing (convex), takes the local minimum at point $y=y_{2}$ and increases on $\left(y_{2}, \infty\right)$ to $+\infty$. It becomes concave at point $y=y_{3}>y_{2}$. Since $H_{1}(y)$ is decreasing on $\left(y_{0}, \infty\right)$, it is clear that there exists a point $y^{*} \in\left(F\left(P_{b}(c), \infty\right)\right.$ such that $H_{1}(y) \leq H_{2}(y, c)$ on $\left(y^{*}, \infty\right)$.

It follows that all we need is to find the linear function

$$
W(y, c)=B_{1}(c) y+B_{2}(c)
$$


that meets smoothly $H_{1}(y)$ and $H_{2}(y)$ together with the respective tangency points, say $y_{a}$ and $y_{b}$. Once found, the value function in the transformed space is

$$
W(y, c)= \begin{cases}H_{1}(y), & y \in\left[F(0), y_{a}(c)\right] \\ B_{1}(c) y+B_{2}(c), & y \in\left(y_{a}(c), y_{b}(c)\right) \\ H_{2}(y, c), & y \in\left[y_{b}(c), \infty\right)\end{cases}
$$

Then the value function on $\left(P_{m}(c), P_{d}(c)\right)$ (in the original space) is

$$
\bar{J}_{1}(p, c)=\varphi(p) W(F(p), c)=B_{1}(c) \psi(p)+B_{2}(c) \varphi(p)=B_{1}(c) p^{\lambda_{1}}+B_{2}(c) p^{\lambda_{2}}
$$

and the threshold levels are given by $P_{m}(c)=F^{-1}\left(y_{a}(c)\right)$ and $P_{d}(c)=F^{-1}\left(y_{b}(c)\right)$. Finally, $V_{1}(\cdot)=$ $\bar{J}_{1}(\cdot)+g(\cdot)$. This completes the proof to (2.6) for any given $c$ that satisfies $c(1-\theta) / r>\gamma$. Note that one can solve the other problems in this paper in the same way by using the appropriate $H_{i}$ functions all computed in this section.

\subsection{Proof of Proposition 2.5}

The proof of the existence and uniqueness of the value function and the optimal threshold levels for this problem is similar to that of Proposition 2.2. We have

$$
\left(V_{2}(p, \bar{c})+D(p, \bar{c})-I\right)-V_{2}(p, \bar{c})=\frac{\bar{c}}{r}-I+\left(2 \gamma-\frac{\bar{c}}{r}\right)\left(\frac{p}{P_{b}(\bar{c})}\right)^{\lambda_{2}} .
$$

In light of the debt value equation (2.7), the right hand side of the last equation is positive if $p>P_{d}$ and negative if $p<P_{d}$ since $\partial D(p, \bar{c}) / \partial p>0$ if $\bar{c} / r>2 \gamma$. Note that the last inequality always holds under the assumption and $P_{d}:=P_{d}(\bar{c})$. Now consider the function

$$
f_{3}(x, c) \triangleq V_{2}(x, c)+D(x, c)-I-g(x)
$$

and its transformed function $H_{3}(y, c) \triangleq f_{3}\left(F^{-1}(y), c\right) / \varphi\left(F^{-1}(y)\right)$

$$
H_{3}(y, \bar{c})= \begin{cases}-\frac{1}{r-\mu} y^{\frac{1-\lambda_{2}}{\lambda_{1}-\lambda_{2}}}+\left(2 \gamma+\frac{\xi}{r}-I\right) y^{\frac{-\lambda_{2}}{\lambda_{1}-\lambda_{2}}}, & y \in\left[F(0), F\left(P_{b}(\bar{c})\right)\right], \\ \frac{1}{r-\mu} y^{\frac{1-\lambda_{2}}{\lambda_{1}-\lambda_{2}}}-\left(\frac{\xi-\theta \bar{c}}{r}+I\right) y^{\frac{-\lambda_{2}}{\lambda_{1}-\lambda_{2}}}+\left(-K(\bar{c})+2 \gamma-\frac{\bar{c}}{r}\right)\left(1 / P_{b}(\bar{c})\right)^{\lambda_{2}}, & y \in\left[F\left(P_{b}(\bar{c})\right), \infty\right) .\end{cases}
$$

From the above argument, we have $H_{2}(y, \bar{c}) \geq H_{3}(y, \bar{c})$ on $\left[F(0), F\left(P_{d}\right)\right]$ and $H_{2}(y, \bar{c})<H_{3}(y, \bar{c})$ on $\left(F\left(P_{d}\right), \infty\right)$. This together with the fact that $H_{3}(y, \bar{c})$ becomes concave and increasing eventually, implies that the smallest linear majorant of $H_{1}$ and $H_{3}$ must dominate $W(y, \bar{c})$ (which is the smallest concave majorant of $H_{1}$ and $H_{2}$ in the proof of Proposition 2.2). That is, $V_{1}(p, \bar{c}) \leq \bar{V}_{1}(p, \bar{c})$ for $p \in \mathbb{R}_{+}$.

\subsection{Analysis of Equations (2.13), (2.14) and (2.15)}

First, Assumption 2.1-(b) means that on the set $\left\{\tau_{d}<\tau_{m}\right\}$, we set that the event $\left\{\Delta \circ \theta\left(\tau_{d}\right)<\tau_{m}\right\}$ has probability one. Here $\theta(\cdot)$ is the shift operator (see, e.g. Karatzas and Shreve [14]). Following the similar method to the proof of Proposition 2.2, equation (2.13) becomes

$$
\begin{aligned}
& V_{1}^{\Delta}(p, c)-g(p)=\sup _{\tau_{m}, \tau_{d} \in \mathcal{S}} \mathbb{E}^{p}\left[e^{-r\left(\tau_{d}+\Delta\right)}\left(V_{2}\left(P_{\tau_{d}+\Delta}, c\right)-g\left(P_{\tau_{d}+\Delta}\right)\right) 1_{\left\{\tau_{d}+\Delta<\tau_{m}\right\}}\right. \\
&\left.+e^{-r \tau_{m}}\left(\gamma-g\left(P_{\tau_{m}}\right)\right) 1_{\left\{\tau_{d}+\Delta>\tau_{m}\right\}}\right] .
\end{aligned}
$$


Since we assume that $\tau_{d}$ is a hitting time of the diffusion to some state (i.e., threshold strategy), by conditioning upon the value of $P_{\tau_{d}}$, the first term on the right-hand side of (5.5) becomes

$$
\begin{aligned}
& \mathbb{E}^{p}\left[\mathbb{E}^{p}\left[e^{-r\left(\tau_{d}+\Delta\right)}\left(V_{2}\left(P_{\tau_{d}+\Delta}, c\right)-g\left(P_{\tau_{d}+\Delta}\right)\right) 1_{\left\{\tau_{d}+\Delta<\tau_{m}\right\}} \mid \mathcal{F}_{\tau_{d}}\right]\right] \\
& =\mathbb{E}^{p}\left[e^{-r \tau_{d}} 1_{\left\{\tau_{d}<\tau_{m}\right\}} \mathbb{E}^{p}\left[e^{-r \Delta}\left(V_{2}\left(P_{\tau_{d}+\Delta}, c\right)-g\left(P_{\tau_{d}+\Delta}\right)\right) 1_{\left\{\tau_{d}+\Delta \circ \theta\left(\tau_{d}\right)<\tau_{m}\right\}} \mid \mathcal{F}_{\tau_{d}}\right]\right]
\end{aligned}
$$

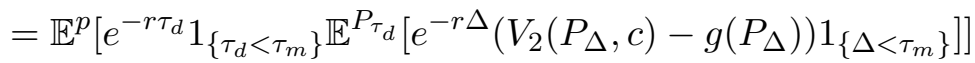

$$
\begin{aligned}
& =\mathbb{E}^{p}\left[e^{-r \tau_{d}} 1_{\left\{\tau_{d}<\tau_{m}\right\}} \mathbb{E}^{\left.P_{\tau_{d}}\left[e^{-r \Delta}\left(V_{2}\left(P_{\Delta}, c\right)-g\left(P_{\Delta}\right)\right)\right]\right]}\right.
\end{aligned}
$$

where the last line is due to Assumption 2.1-(b). Hence from (2.4),the reward function at time $\tau_{d}$ is

$$
\begin{aligned}
f_{4}(x, c): & =e^{-r \Delta}\left(\frac{1}{r-\mu} \cdot x \mathbb{E}\left[e^{q \Delta+\sigma B_{\Delta}}\right]-\frac{\xi+(1-\theta) c}{r}-K(c) \cdot\left(1 / P_{b}(c)\right)^{\lambda} \cdot x^{\lambda} \mathbb{E}\left[e^{q \lambda \Delta+\sigma \lambda B_{\Delta}}\right]\right) \\
& =e^{-r \Delta}\left(\frac{M_{1}}{r-\mu} x-\frac{\xi+(1-\theta) c}{r}-K(c) \cdot\left(1 / P_{b}(c)\right)^{\lambda} \cdot M_{2} x^{\lambda}\right)
\end{aligned}
$$

on $x \in\left[P_{b}(c), \infty\right)$ where $q:=\mu-\frac{1}{2} \sigma^{2}, M_{1}:=\exp \left(q \Delta+\frac{\sigma^{2} \Delta}{2}\right), M_{2}:=\exp \left(q \lambda \Delta+\frac{(\sigma \lambda)^{2} \Delta}{2}\right)$, and $K(c)$ as in (5.2). This equation is of the same form as $f_{2}(x, c)$ except for the constant multipliers $M_{1}$ and $M_{2}$. Since both constants are positive, the analysis for $f_{2}(x, c)$ in Appendix 5.2 applies to this case: Similarly to $H_{2}$, define $H_{4}(y, c) \triangleq f_{4}\left(F^{-1}(y), c\right) / \varphi\left(F^{-1}(y)\right)$ which is

$$
e^{r \Delta} H_{4}(y, c)= \begin{cases}-\frac{M_{1}}{r-\mu} y^{\frac{1-\lambda_{2}}{\lambda_{1}-\lambda_{2}}}+\frac{\xi}{r} y^{\frac{-\lambda_{2}}{\lambda_{1}-\lambda_{2}}}, & y \in\left[F(0), F\left(P_{b}(c)\right)\right], \\ \frac{M_{1}}{r-\mu} y^{\frac{1-\lambda_{2}}{\lambda_{1}-\lambda_{2}}}-\frac{\xi+(1-\theta) c}{r} y^{\frac{-\lambda_{2}}{\lambda_{1}-\lambda_{2}}}-K(c) M_{2}\left(1 / P_{b}\right)^{\lambda_{2}}, & y \in\left[F\left(P_{b}(c)\right), \infty\right) .\end{cases}
$$

On the other hand, the second term on the right-hand side of (5.5) becomes $\mathbb{E}^{p}\left[e^{-r \tau_{m}}\left(\gamma-g\left(X_{\tau_{m}}\right) 1_{\left\{\tau_{d}>\tau_{m}\right\}}\right]\right.$ due to Assumption 2.1-(b) again:

$$
1_{\left\{\tau_{d}+\Delta>\tau_{m}\right\}}=1_{\left\{\tau_{d}>\tau_{m}\right\}}+1_{\left\{\tau_{d}<\tau_{m}\right\}} 1_{\left\{\Delta \circ \theta\left(\tau_{d}\right)>\tau_{m}\right\}}=1_{\left\{\tau_{d}>\tau_{m}\right\}}
$$

Thus, the reward function at time $\tau_{m}$ is the same as $f_{1}(x, c)$ in the proof of Proposition 2.2. The similar analysis of (2.15) leads to the reward function stopped at $\tau_{d}$ as

$$
e^{r \Delta} f_{6}(x, c):= \begin{cases}-\frac{M_{1}}{r-\mu} x+\left(2 \gamma+\frac{\xi}{r}-I\right), & x \in\left(0, P_{b}(c)\right), \\ \frac{M_{1}}{r-\mu} x-\left(\frac{\xi-\theta c}{r}+I\right)+\left(2 \gamma-K(c)-\frac{c}{r}\right) M_{2}\left(1 / P_{b}(c)^{\lambda} x^{\lambda},\right. & x \in\left[P_{b}(c), \infty\right),\end{cases}
$$

which is, after the transformation,

$$
e^{r \Delta} H_{6}(y, c)= \begin{cases}-\frac{M_{1}}{r-\mu} y^{\frac{1-\lambda_{2}}{\lambda_{1}-\lambda_{2}}}+\left(2 \gamma+\frac{\xi}{r}-I\right) y^{\frac{-\lambda_{2}}{\lambda_{1}-\lambda_{2}}}, & y \in\left[F(0), F\left(P_{b}(c)\right)\right] \\ \frac{M_{1}}{r-\mu} y^{\frac{1-\lambda_{2}}{\lambda_{1}-\lambda_{2}}}-\left(\frac{\xi-\theta c}{r}+I\right) y^{\frac{-\lambda_{2}}{\lambda_{1}-\lambda_{2}}}+\left(2 \gamma-K(c)-\frac{c}{r}\right) M_{2}\left(1 / P_{b}(c)\right)^{\lambda_{2}}, & y \in\left[F\left(P_{b}(c)\right), \infty\right) .\end{cases}
$$

The reward at time $\tau_{m}$ is again $f_{1}(x, c)$.

Finally, in the case of (2.14), the function we need after the transformation is

$$
e^{r \Delta} H_{5}(y)= \begin{cases}-\frac{M_{1}}{r-\mu} y^{\frac{1-\lambda_{2}}{\lambda_{1}-\lambda_{2}}}-\left(2 \gamma+\frac{\xi}{r}\right) y^{\frac{-\lambda_{2}}{\lambda_{1}-\lambda_{2}}}, & y \in\left[F(0), F\left(P_{c}\right)\right], \\ \frac{M_{1}}{r-\mu} y^{\frac{1-\lambda_{2}}{\lambda_{1}-\lambda_{2}}}-\left(\frac{\xi}{r}+I\right) y^{\frac{-\lambda_{2}}{\lambda_{1}-\lambda_{2}}}+2 M_{2}\left(\gamma-\frac{P c}{r-\mu}+\frac{\xi}{r}\right)\left(1 / P_{c}\right)^{\lambda_{2}}, & y \in\left[F\left(P_{c}\right), \infty\right) .\end{cases}
$$




\section{References}

[1] F. Black and J. C. Cox. Valuing corporate securities: Some effects of bond indenture provisions. Journal of Finance, 31:351-367, 1976.

[2] F. Black and M. Scholes. The pricing of options and corporate liabilities. Journal of Political Economy, 81:637-659, 1973 .

[3] M. J. Brennan. Corporate finance over the past 25 years. Financial Management, 24:9-22, 1995.

[4] M. J. Brennan and E. S. Schwartz. Evaluating natural resource investments. Journal of Business, 58:135-157, 1986.

[5] A. Cadenillas, J. Civitanic, and F. Zapatero. Leverage decision and manager compensation with choice of effort and volatility. Journal of Financial Economics, 73:71-92, 2004.

[6] P. D. Childs, D. C. Mauer, and S. H. Ott. Interactions of corporate financing and investment decisions: The effect of agency conflicts. Journal of Financial Economics, 76:667-690, 2005.

[7] S. Dayanik and I. Karatzas. On the optimal stopping problem for one-dimensional diffusions. Stochastic Processes and Their Applications, 107(2):173-212, 2003.

[8] A. K. Dixit. Entry and exit decisions under uncertainty. Journal of Political Economy, 97:620-638, 1989.

[9] A. K. Dixit and R. S. Pindyck. Investment Under Uncertainty. Princeton University Press, Princeton, New Jersey, 1994.

[10] D. Duffie. Dynamic Asset Pricing Theory. Princeton University Press, 3rd edition, 2001.

[11] E. Dynkin. Markov Processes vol. II. Springer-Verlag, 1965.

[12] C. Hennessy. Tobin's q, debt overhang, and investment. Journal of Finance, 59:1717-1742, 2004.

[13] M. C. Jensen and W. H. Meckling. Theory of the firm: Managerial behavior, agency costs and ownership structure. Journal of Financial Economics, 3:305-360, 1976.

[14] I. Karatzas and S. E. Shreve. Browninan Motion and Stochastic Calculus, 2nd Edition. Springer-Verlag, New York, 1991.

[15] H. Leland. Corporate debt value, bond convenants, and optimal capital structure. Journal of Finance, 49:1213-1252, 1994.

[16] H. Leland. Agency costs, risk measurement, and capital structure. Journal of Finance, 53:1213-1243, 1998.

[17] D. C. Mauer and S. Sarkar. Real options, agency conflicts, and optimal capital structure. Journal of Banking and Finance, 29:1405-1428, 2005.

[18] R. McDonald and D. Siegel. The value of waiting to invest. Quarterly Journal of Economics, 101:707-728, 1986.

[19] P. Mella-Barral and W. Perraudin. Strategic debt service. Journal of Finance, 52:531-556, 1997.

[20] A. S. Mello and J. E. Parsons. Measuring the agency cost of debt. Journal of Finance, 47:1887-1903, 1992.

[21] R. C. Merton. On the pricing of corporate debt: The risk structure of interest rates. Journal of Finance, 29:449-470, 1974.

[22] E. Morellec. Can managerial discretion explain observed leverage ratios? Review of Financial Studies, $17: 257-294,2004$

[23] S. C. Myers. Determinants of corporate borrowing. Journal of Financial Economics, 5:147-175, 1977.

[24] R. Parrino and M. S. Weisbach. Measuring investment distortions arising from stockholder-bondholder conflicts. Journal of Financial Economics, 53:3-42, 1999.

[25] S. Titman and S. Tsyplakov. A dynamic model of capital structure, 2002. Working paper, University of Texas at Austin.

[26] L. Zingales. In search of new foundations. Journal of Finance, 55:1623-1653, 2000. 